\title{
A three-ring circus: discussing the ethical issues of three-parent embryos
}

\section{Ljiljana Nikolajev \& Sahil Kumar}

\section{McGill University}

As research of human genetics progresses, there appears to be a wavering boundary between ethical and unethical scientific investigation. However, as discoveries are made, current ordinance may not condone the use of such controversial techniques in practice. In February 2015, the United Kingdom Members of Parliament passed an amendment to the Human Fertilisation and Embryology Act, leading to the first policy reform for oocyte modification ${ }^{1}$. This contentious amendment to the invitro fertilisation (IVF) technique will permit the exchange of defective mitochondrial DNA (mtDNA), the cause of mitochondrial disease, for healthy mtDNA from a donor's egg, effectively creating a "three-parent zygote." In the United States, the Dickey-Wicker Amendment prohibits funding of "the creation of human embryos for research purposes or research in which a human embryo is harmed or destroyed"2; however, the Food and Drug Administration has discussed the matter of oocyte modification at a hearing in the court of public opinion in $2014^{4}$. In Canada, the Assisted Human Reproduction Act restricts "[creating] an embryo from a cell or part of a cell taken from an embryo or fetus or transplant an embryo so created into a human being. ${ }^{5}$ This new policy reform in the UK may change the tides in favour of approving mitochondrial replacement technologies in Canada and the United States.

Mitochondrial disease can occur due to DNA mutations in energy-producing mitochondria or mutations in nuclear DNA, compromising overall mitochondrial function ${ }^{2}$. Mitochondrial disease primarily affects tissues that require high levels of adenosine triphosphate, such as the brain, muscles, heart, and kidneys ${ }^{2}$. It is estimated to affect 1 in 4000 children born in the United States at a single or multiple-organ level, resulting in deafness, blindness, muscle weakness, cognitive impairments, organ failure, and death ${ }^{2}$. The rationale for replacement therapy (RT) would be to improve the prospect of survival of an individual highly susceptible to mitochondrial disease ${ }^{6}$.

During reproduction, 37 genes from mtDNA are transmitted to the offspring through maternal cytoplasm (compared to the $20,000+$ genes from parental chromosomal DNA) ${ }^{2}$. Individuals with mitochondrial disease often have a mixture of normal and mutant mtDNA - a threshold of $60 \%$ $90 \%$ mutant mtDNA dictates the abnormal phenotype ${ }^{2}$. Currently, two approaches of IVF are employed for mitochondrial replacement therapy: pronuclear transfer or maternal spindle transfer (see Figure 1). Pronuclear transfer involves the removal of the pronuclei from a fertilised zygote with abnormal mitochondria and transfer into an enucleated donor zygote with normal mitochondria ${ }^{2}$. Alternatively, maternal spindle transfer is a newer technique that involves the exchange of the spindle and associated chromosomes from an unfertilised egg with abnormal mitochondria with a donated, unfertilised egg possessing normal mitochondria, which is subsequently fertilised with spermatozoa via intracytoplasmic sperm injection (ICSI) $)^{2}$. Under the Assisted Human Reproduction Act, maternal spindle transfer could be considered a legal practice, as the biological material used is removed from an unfertilised egg as opposed to an embryo; hence, this could permit the induction of replacement therapy under current ruling. While RT has shown safety and efficacy in animal models, ${ }^{6}$ controversy as to whether this technique is ethical and legal for humans remains. Although mtDNA encodes $0.1 \%$ of the total transmitted DNA and does not contribute to physical traits or personality, ${ }^{7}$ the legal implication of three biological parents is present - namely the role of the donor and their implication in the child's life. The UK Nuffield Council on Bioethics, which scrutinized all ethical concerns regarding this therapy, arrived to the conclusion that the mtDNA donor could not be considered as a "third" parent, as only part of the egg is used and no nuclear DNA from the third-party is transferred ${ }^{8}$. Moreover, adversaries 
express worries as to whether allowing such therapies would lead to a slippery slope of eugenics and "designer" babies; conversely, the mtDNA genes function to regulate energy homeostasis and would only improve survival of the individual highly susceptible to a mitochondrial disease, but not alter traits encoded by nuclear chromosomes. Current options for women at risk of passing the disease are to adopt, choose to not conceive, or take the risk of sequential stillborn babies ${ }^{9}$. Should parents express the desire to conceive healthy, genetically related children, the Nuffield Report stipulates that it would be ethical to allow couples to have access to a reproductive therapy that is adequate for their needs ${ }^{8}$.

The UK has made the first step towards advancement of mtDNA RT and evaluating this technique for humans. However, many important questions remain to beaddressed, such as the implication of "foreign" gene germline transmission to future generations, incompatibilities between the haplotypes of the donor's mtDNA and the mother's nuclear DNA, or the possible epigenetic abnormalities prompting further diseased states $^{2,10}$. The benefits of the therapy are mainly for couples wishing to conceive a child without transmission of the disease, but will not cure those currently living with mitochondrial disease. Although the opposition to the technology may bring about the hiatus of advancing three-parent babies into health action, clinical trials can greatly determine the safety and efficacy of the technique in humans for use in the imminent future ${ }^{10}$.

\section{References}

1. Knapton S. Three-parent babies to be born in Britain as MPs say yes to law change. Telegraph [Internet]. 2015 Feb 3. Available from: http://www. telegraph.co.uk/news/science/science-news/11387179/Three-parentbabies-to-be-born-in-Britain-as-MPs-say-yes-to-law-change.html

2. Amato $P$, Tachibana M, Sparman M, Mitalipov S. Three-parent in vitro fertilization: gene replacement for the prevention of inherited mitochondrial diseases. Fertility and Sterility. 2015 Jan;101(1):31-35.

3. Chinnery PF. Mitochondrial Disorders Overview. GeneReviews; 2000 Jun 8 [updated 2014 Aug 14].

4. Maron DF. Making Babies with 3 Genetic Parents Gets FDA Hearing. Scientific American. 2014 Feb 25.

5. Justice Laws Website. Government of Canada; 2004 Mar 29. Available from: http://laws-lois.justice.gc.ca/eng/annualstatutes/2004_2/page-2.html

6. Callaway E. Reproductive medicine: The power of three. Nature News; 2014 May 21. Available from: http://www.nature.com/news/reproductivemedicine-the-power-of-three-1.15253

7. Baylis $F$. The ethics of creating children with three genetic parents. Reproductive Biomedicine Online, 2013 Jun;26(6):531-534.

8. Hallowell N. Nuffield Council on Bioethics Report: Novel Techniques for the prevention of mitochondrial DNA disorders: an ethical review London: Nuffield Council of Bioethics 2012. Life Sciences Society and Policy. 2012 Sept 15;8(2):29.

9. Griggs J. Mitochondrial replacement vote: What you need to know. NewScientist; 2015 Feb 3. Available from: http://www.newscientist.com/ article/dn26900-mitochondrial-replacement-vote-what-you-need-toknow.html\#.VNvF6VbGwty

10. Mitalipov S, Wolf DP. Clinical and ethical implications of mitochondrial gene transfer. Trends in Endocrinology \& Metabolism, 2014 Jan;25(1):5-7.

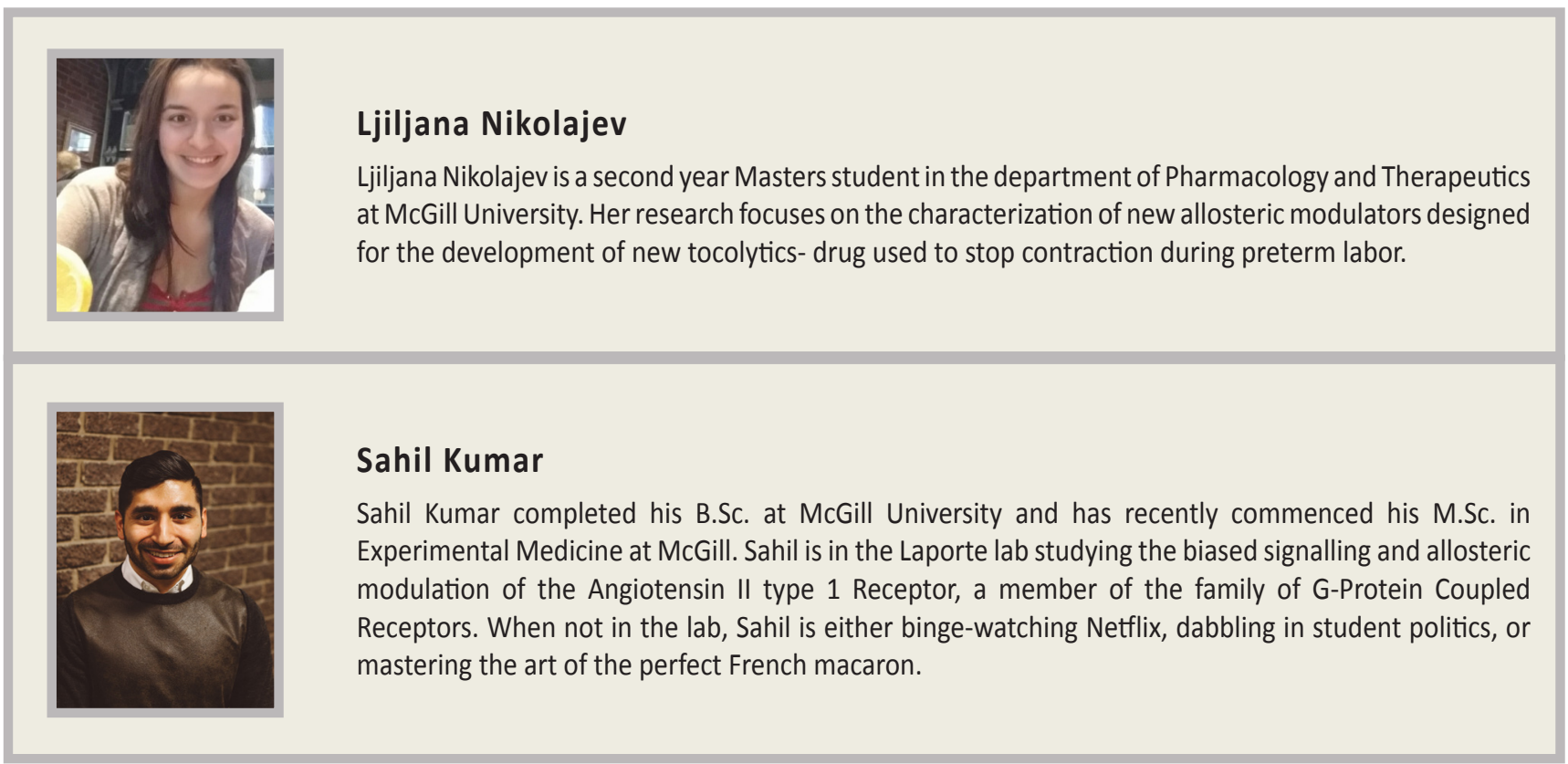

